\title{
Rehabilitation of the Roof Timber Trusses of a Multiuse Pavilion
}

\author{
João H. Negrão ${ }^{a^{*}}$ \\ ${ }^{a}$ Associate Professor, Department of Civil Engineering, University of Coimbra, Coimbra, Portugal.
}

Received 30 August 2020; Accepted 02 November 2020

\begin{abstract}
This paper describes the rehabilitation procedure of the roof timber structure of a multiuse pavilion in Viseu, Portugal. The roof structure consists of a series of parallel double timber trusses, partially concealed above a polyhedral wooden plank-made ceiling. Recently, the support of one of the trusses failed and another one has been assessed as in a prefailure condition. Some load-redistribution and the prompt shore of the structure prevented the generalized collapse. The subsequent inspection and assessment led to the conclusion that the primary cause of the collapse was the failure perpendicular to the grain of the solid timber elements inserted between the double rafters and tie-beams. The replacement of the existing with a steel structure, and the repair and reinforcement of the existing wooden trusses, were considered as intervention possibilities. The latter revealed much cheaper, less time-consuming and in line with the international recommendations on rehabilitation works, and was therefore adopted. An innovative solution, consisting of the replacement of the central timber elements in all the supports, resulted in minimum visual impact and improved the load bearing capability beyond its original value.
\end{abstract}

Keywords: Timber Structures; Rehabilitation; Strengthening; Construction Process; Prosthesis.

\section{Introduction}

In the last decades, a strong shift occurred on the philosophy underneath the rehabilitation/refurbishment works in ancient structures (timber structures included). The ICOMOS (International Council on Monuments and Sites) Recommendations [1] set the path for new approaches focused on the safeguard of patrimonial and heritage values, and much of these guidelines are generally accepted today even when constructions other than monuments, such as private buildings, industrial facilities, etc., are concerned. The heritage issues have been a concern and topic of research and reflection ever since, and some countries with large and sensitive historical and architectural heritage issued standards on rehabilitation of wood structures [2-4] and others, based on those recommendations, as a way to force them into practical application. From among the provisions in those standards, the following particularly conditioned the definition of the rehabilitation solution described further ahead. The exact terms of the provisions were freely adapted to improve clearness of this text:

- The intervention provisions should harmonize with the existing structural context, rather than being concealed in it;

- The rehabilitation solutions shall be reversible, whenever possible;

- The original structural scheme (statics) should be kept;

- The stiffness of the rehabilitated connections should be close to the original values;

- Prosthesis of the same species as the original timber may be used to restore the integrity of an element;

- The durability of the wood shall be ensured with either constructive provisions or application of preservative products;

* Corresponding author: jhnegrao@dec.uc.pt 
- Steel elements (e.g. plates) may be used in traditional dry connections to restore the continuity between two parts of a timber element;

- The connections may be made up with either connectors or structural adhesive bonding (...);

- (Final and) intermediate execution procedures to assess the intervention results should be defined.

The case study reported in this paper concerns the rehabilitation of timber trusses. Such structures have been built for centuries and, in spite of the evolution on materials and analysis and design techniques and power, its basic principles remain unchanged. The heel- or step-joint, with a few possible configurations, is the carpentry joint usually used to connect the rafter and the tie-beam at the supports. Most of the pathologies that put the structural system at risk have to do with failure of these connections, either due to biotic attack or excessive stress, the latter possibly being a consequence of the former. Failure typically occurs due to compression crushing at the front notch (es) or to shear in the tie-beam toe. A comprehensive description of the design methods for these connections may be found in [5]. Some authors have investigated and proposed strengthening and retrofitting techniques for them. Arriaga et al. [6] proposed various arrangements of reinforced epoxy prosthesis. Palma et al. [7] carried out an experimental campaign to disclose the rotational behavior in step-joints and the effect of various stabilizing and reinforcing metallic devices currently used in these connections. Branco et al. [8] produced a similar study, with the emphasis on the ductility of the joint with different reinforcement devices. Most research work in this area is focused on the mechanics and stress distribution in the joint interfaces [9-11] or its behavior under seismic action [12, 13], as the low ductility and poor performance of these connections raise concerns from this point of view. It must be underlined, however, that none of the usual failure modes described above was the cause for the present collapse, and that is what makes this case study so particular.

\subsection{Structural and Functional Characterization}

The Central Viseu Lyceum was established in 1849, its name having been changed to "Alves Martins" in 1911, little after the Republic proclamation. The actual facilities were built in 1948, within the frame of an extensive governmental scholar constructions program. Figure 1-left shows an overview of the scholar complex, the yellow circle highlighting the pavilion, whose upper floor is taken by the Multiuse Room, shown in Figure 1-right from the outside. The pavilion is a 2-florey building. The ground floor hosts the school lunchroom. The upper floor was formerly used as the school gymnasium, but the recent construction of a larger and modern one allowed this space to be disaffected from that original use and being reassigned as a multiuse space. It is rectangular in shape, with inner dimensions of $14 \times 20 \mathrm{~m}$. The main entrance is located in the North side, a small stage existing in the opposite side. The roof is of 4-sided hip type, with slopes of $25^{\circ}$.

The superstructure and the first floor are made with reinforced concrete. The pylons are peripheral and placed every $4 \mathrm{~m}$, the space between being filled with masonry walls in the bottom $3 \mathrm{~m}$ and wide windows in the remaining storey height. The roof is sustained by maritime pine timber trusses. Along the long sides of the building, these so-called main trusses are parallel and $14 \mathrm{~m}$ long, their supports being located on the top of the concrete pylons. Close to the short sides of the building, the trusses have a skewed arrangement, parallel to the roof ridges, and the load distribution scheme is more complex. The 4 main trusses visible from the inside (Figure 2 (left)) have double rafters and tiebeams, with a free space between of $10 \mathrm{~cm}$, there the single diagonals and hangers fit. The side trusses and the skewed trusses close to the shorter building sides have no duplicated elements. The double rafters and tie-beams are made up with $120 \times 240 \mathrm{~mm}$ cross section timber elements. The diagonals and hangers have a constant width of $120 \mathrm{~mm}$ and a depth of either 120 or $200 \mathrm{~mm}$. The roof is made up of timber planks and has a polyhedral shape, with a horizontal $2 \mathrm{~m}$-wide perimeter strip, see Figure 2 (left) and scheme of Figure 2 (right).
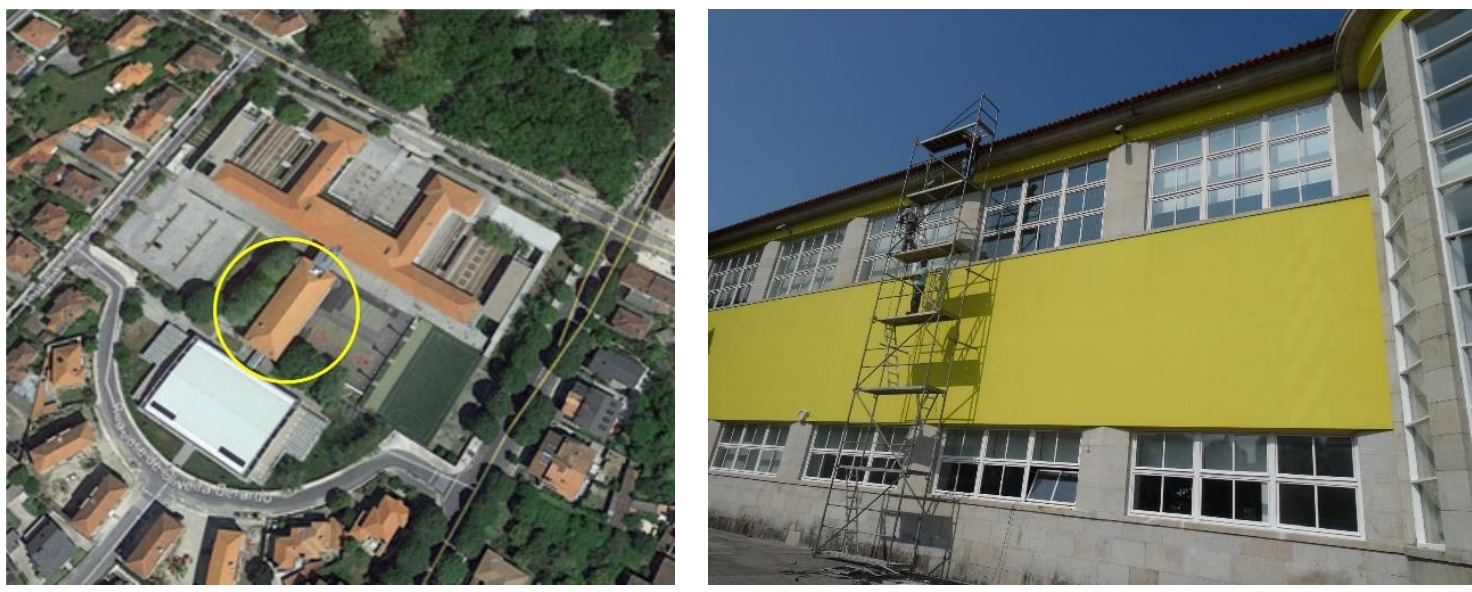

Figure 1. School overview (left); Multiuse Pavilion (right) 
In the following sections, the methodology used to assess the present condition and the proposed intervention procedures are described. Section 2 details the inspection and diagnosis of the timber roof, where the causes and nature of the observed failures was identified and the general intervention needs were identified. Some discussion and detailing on the rehabilitation solution is provided in Section 3, while Section 4 describes the programmed execution procedures as well as the additional inspection work whose need became evident during the execution. The text is closed with the most relevant conclusions drawn from the work. The flowchart in Figure 3 illustrates the whole decision process.
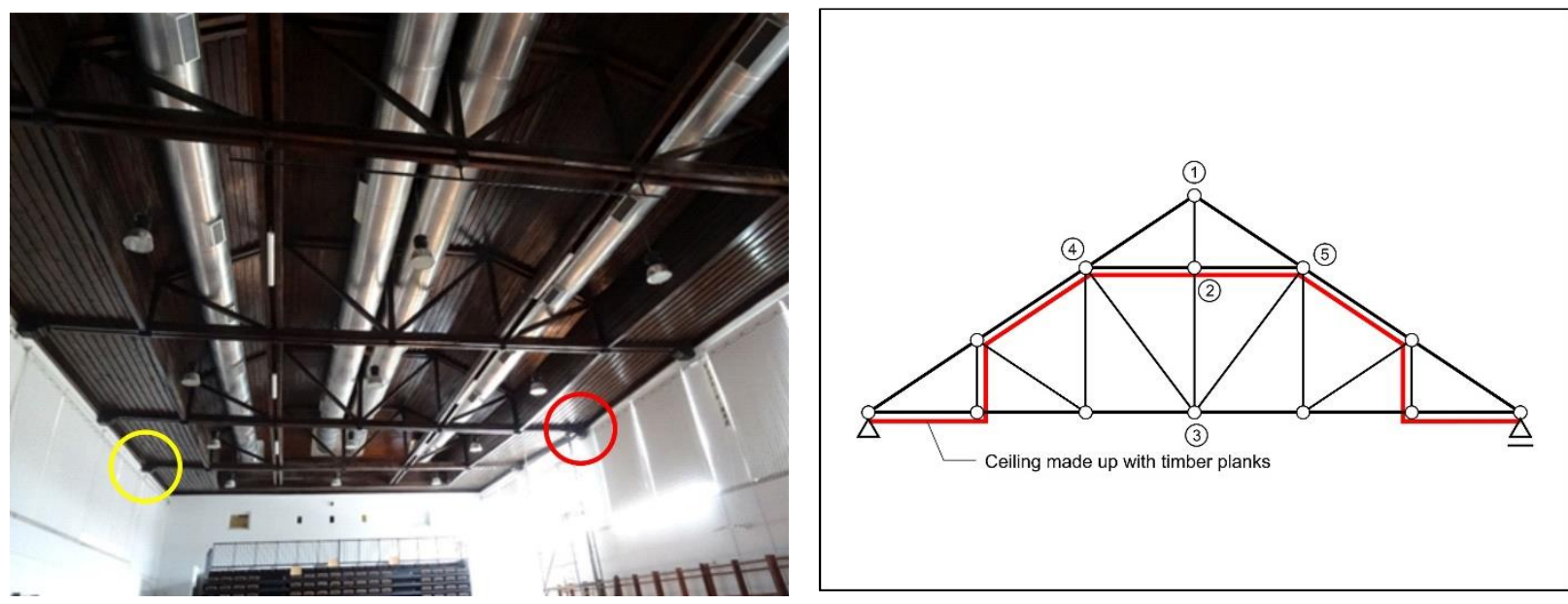

Figure 2. Inner view of the room and damaged supports (left); Scheme of the ceiling (right)

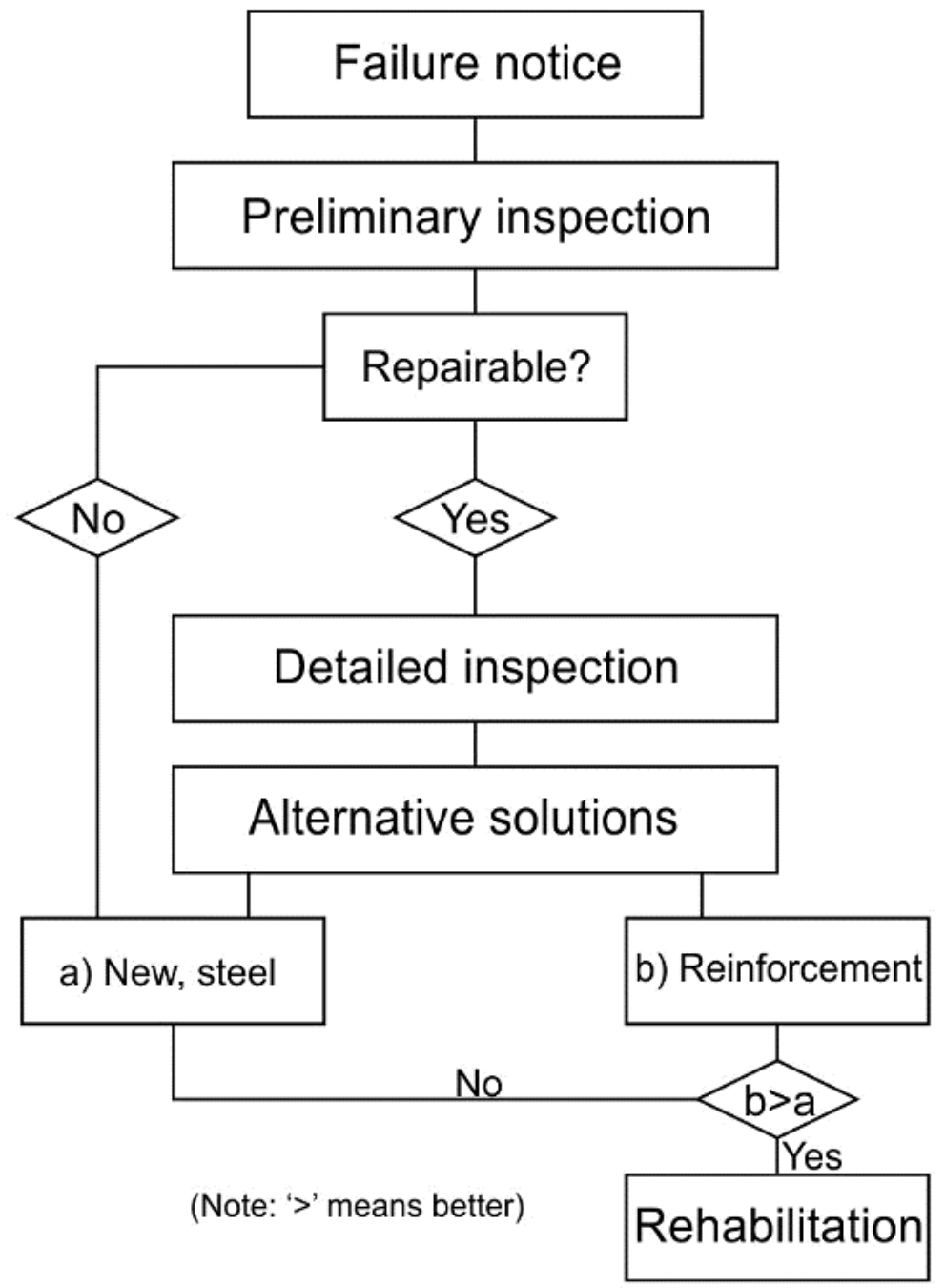

Figure 3. Flowchart of the decision process 


\section{Inspection and Diagnosis of the timber structure}

\subsection{Support Failure}

In early September 2017, coincident with the beginning of the scholar year, the collapse of one support (red circle in Figure 2-a) of one of the main trusses was detected, as well as the pre-failure condition of one support (yellow circle) of another truss. Spurious load-redistribution provided by secondary elements, even if not specifically accounted for in design, and the prompt shore of the affected trusses, in order to alleviate those elements and stop the progression of the failure process, prevented the generalized failure of the affected trusses. ITeCons [14], a research and consultancy institute hosted within the University of Coimbra, was contracted for the inspection and assessment work and, later on, for the production of the rehabilitation design. The later detailed inspection of the support area revealed that the cause of the collapse was tension failure perpendicular to the grain in a joining wooden member. Figure 4-left details the joint (some drawing simplification was introduced in the rafter and tie beam ends, for clearness), while Figure 4-right is a scheme of the observed failure mechanism.

Various possible explanations for the adoption of this joint arrangement can be drawn, namely: $i$ ) the insufficient length of the rafters and the tie beams to allow the force equilibrium in the theoretical support point (situation schematically represented in Figure 4-left; $i i)$ the insufficient length of the tie-beam toe to withstand the horizontal shear force component; iii) the eccentric concurrent point of the rafters and the tie-beams with respect to the theoretical support point, originating a binary that must be equilibrated by bending of these bars; $i v$ ) the centering of the reaction in the middle of the support in the longitudinal (wall) direction; $v$ ) a combination of these.
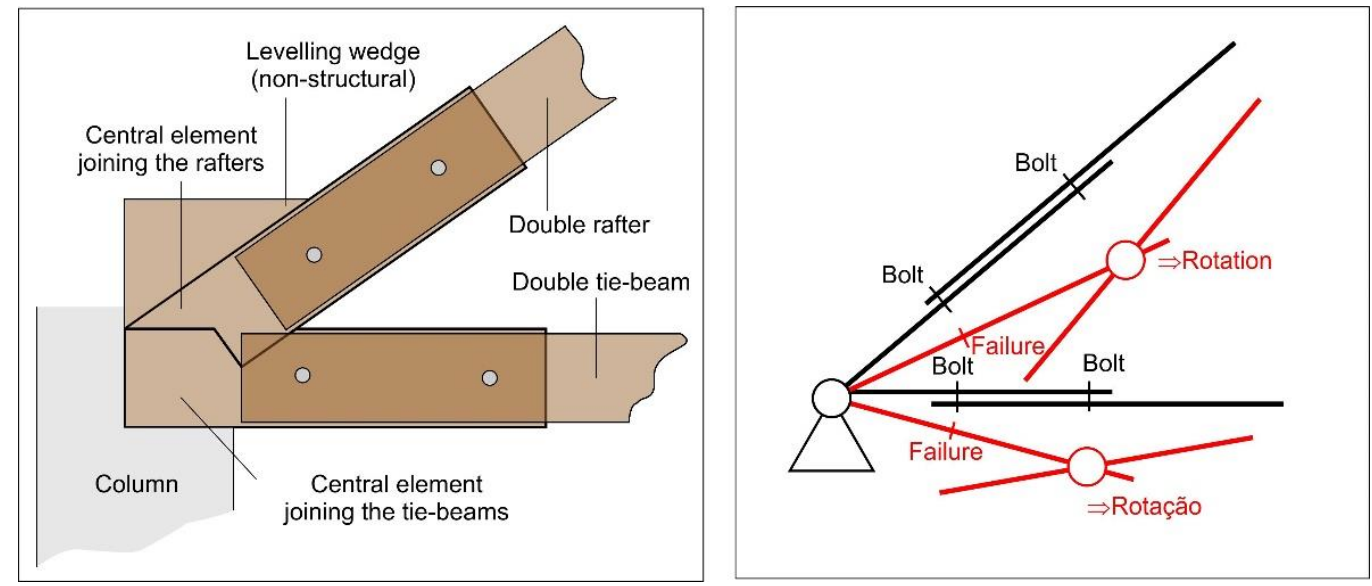

Figure 4. Joint arrangement at the support (left); Potential (observed) failure mechanism (right)

For better understanding, the sequence of events that caused the failure schematically illustrated in Figure 4-right is represented in the following figures, which agree in an exemplar manner with the photographic record of the accident collected on site.

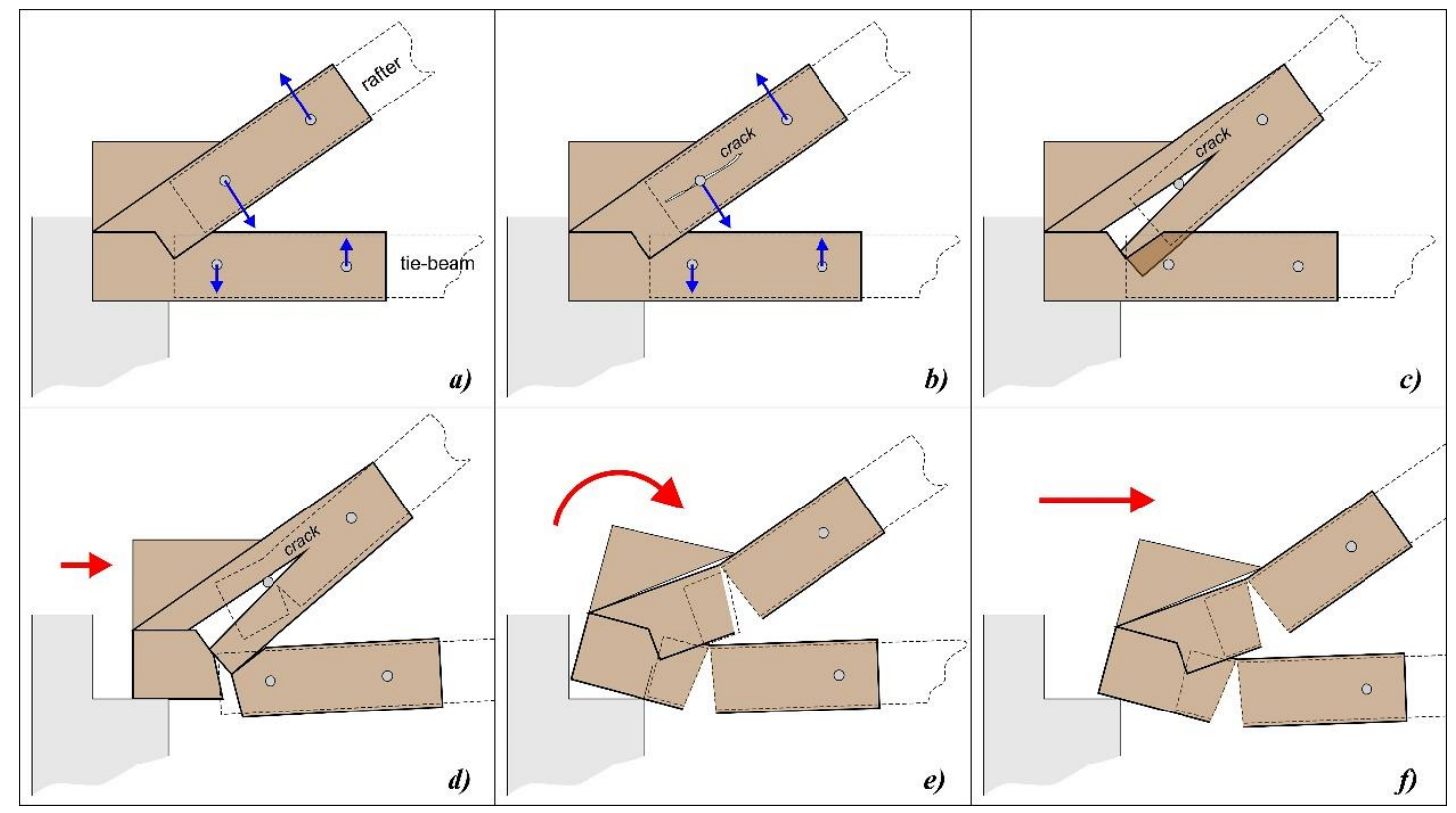

Figure 5. Sequence of events that led to the support collapse 

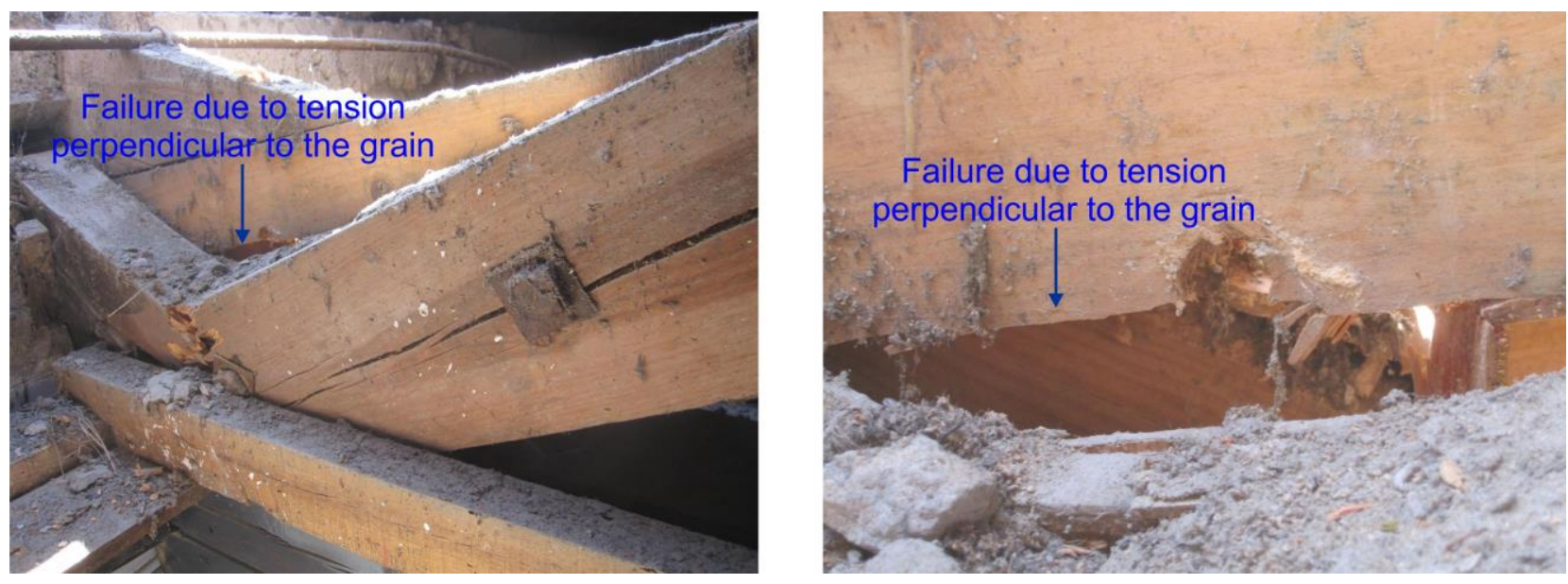

Figure 6. Failure of the central timber piece (left); Connection failure (right)

Figure 6 depicts actual representations of this mechanism. In Figure 6-right and in first plane, the central timber piece and the fracture originated at the bolt hole may be seen. The developed failure mechanism is seen in Figure 6left. The rafters' connections failed first and the resulting rotation caused the failure of the tie-beams below.

\subsection{Other Pathologies}

Besides supports' failures, critical occurrences that caused the need for the structural assessment and rehabilitation works, the inspection revealed other weaknesses, of variable damage consequences but, in every case, requiring corrective reinforcement provisions. The most concerning were the incipient failures of some "Jupiter ray" carpentry connections (Figure 7-a), existing in variable locations in all the tie-beams. These were caused by shear failure of the imbricating notches, as shown in Figure 7-b.
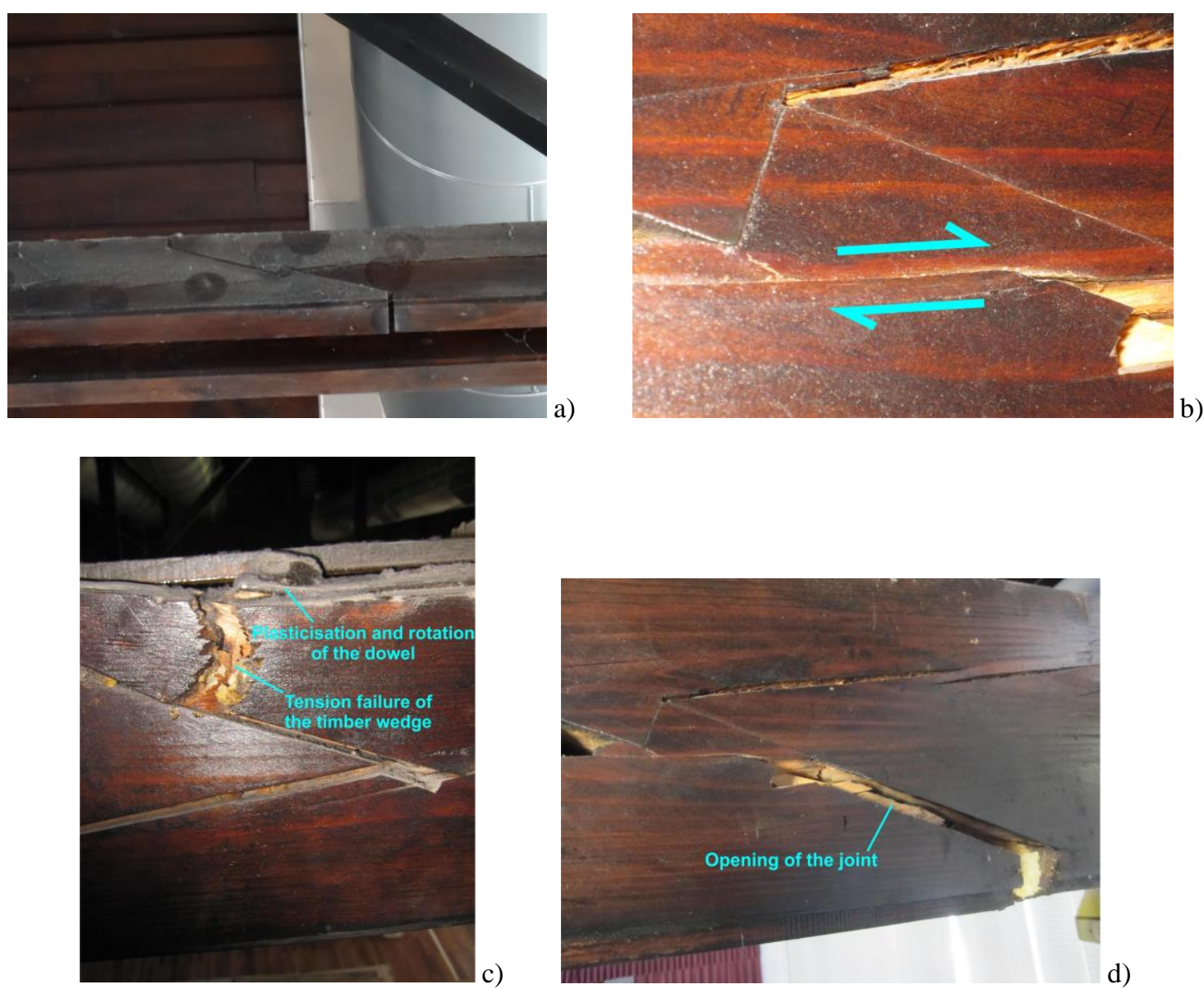

Figure 7. a) Joint overview; b) Shear failure; c) Dowel plasticization; d) Joint opening 
Although the geometry is generically correct, the notch depth - and, consequently, the length of the shear surface is too short. According to the good practice, this depth should be 1/3 of that of the elements being joined, much more than what can be seen in the figure. Such failure is likely to cause the whole truss collapse, which did not happen due to the redundancy provided by the cross-through steel dowel used to prevent the separation of the parts, see Figure 7-c. However, the transfer of the heel force to the dowel caused its plasticization and rotation, with the consequent opening of the joint (Figure 7-d) and the tension failure of the wood wedge undergoing the embedding force of the dowel, also visible in Figure 7-c.

The inspection of the structure concealed by and above the wooden ceiling showed that the main structural elements (trusses, beams and bracing elements, Figure 8-left were in generally good condition, with local and moderate beetle attack and no evidence of decay. However, several secondary elements, such as ceiling supporting clapboards and ceiling planks were severely attacked by beetles (Figure 8-right, with no other repair solution but its replacement. The most likely causes for this difference are the inferior timber grade of the latter and its larger vulnerability to egg deposition and attack, given their smaller size and larger specific surface.

During the rehabilitation works, two further anomalies not detected during the inspection stage were found, one critical and the other secondary regarding safety issues. The former was a broken tie-beam, caused by the near presence of a large-size knot reducing the net cross-section (Figure 9-left). The latter was the excessive slope of a cantilever part of the wooden ceiling, due to the deformation of the supporting structure (Figure 9-right).
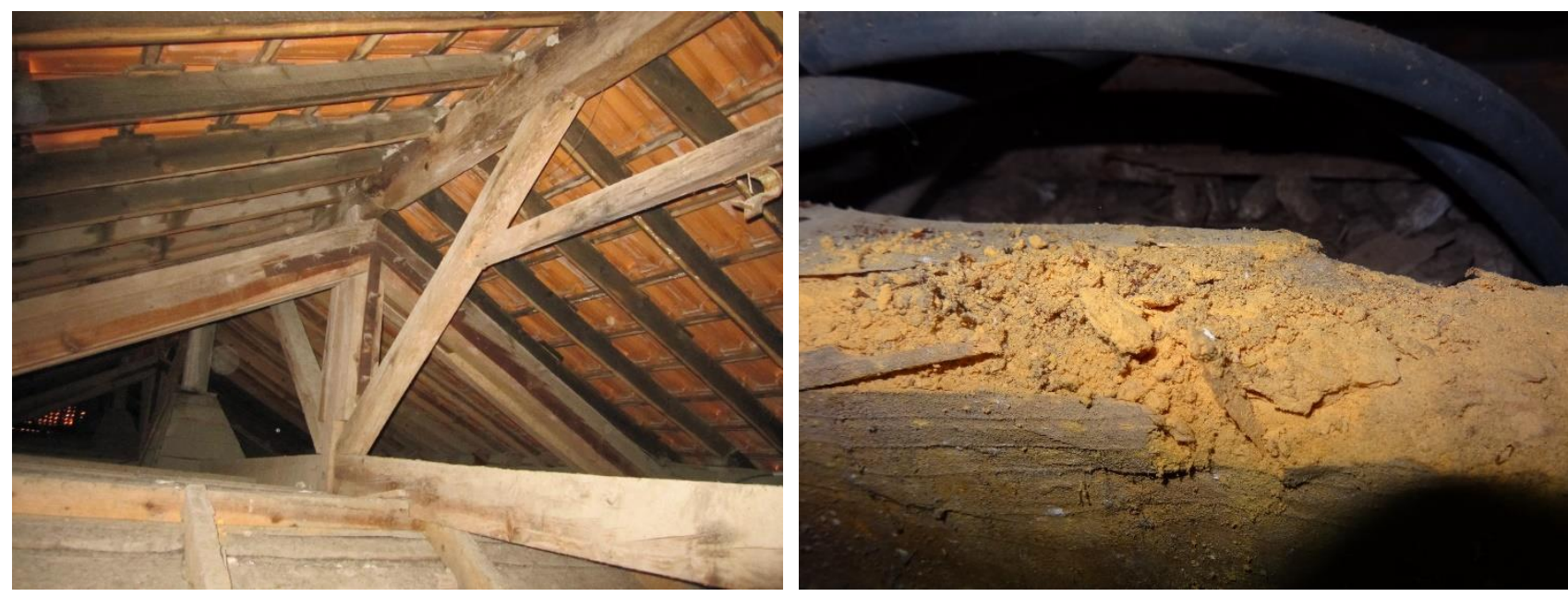

Figure 8. Main elements in good condition (left); Severe attack of secondary elements (right)
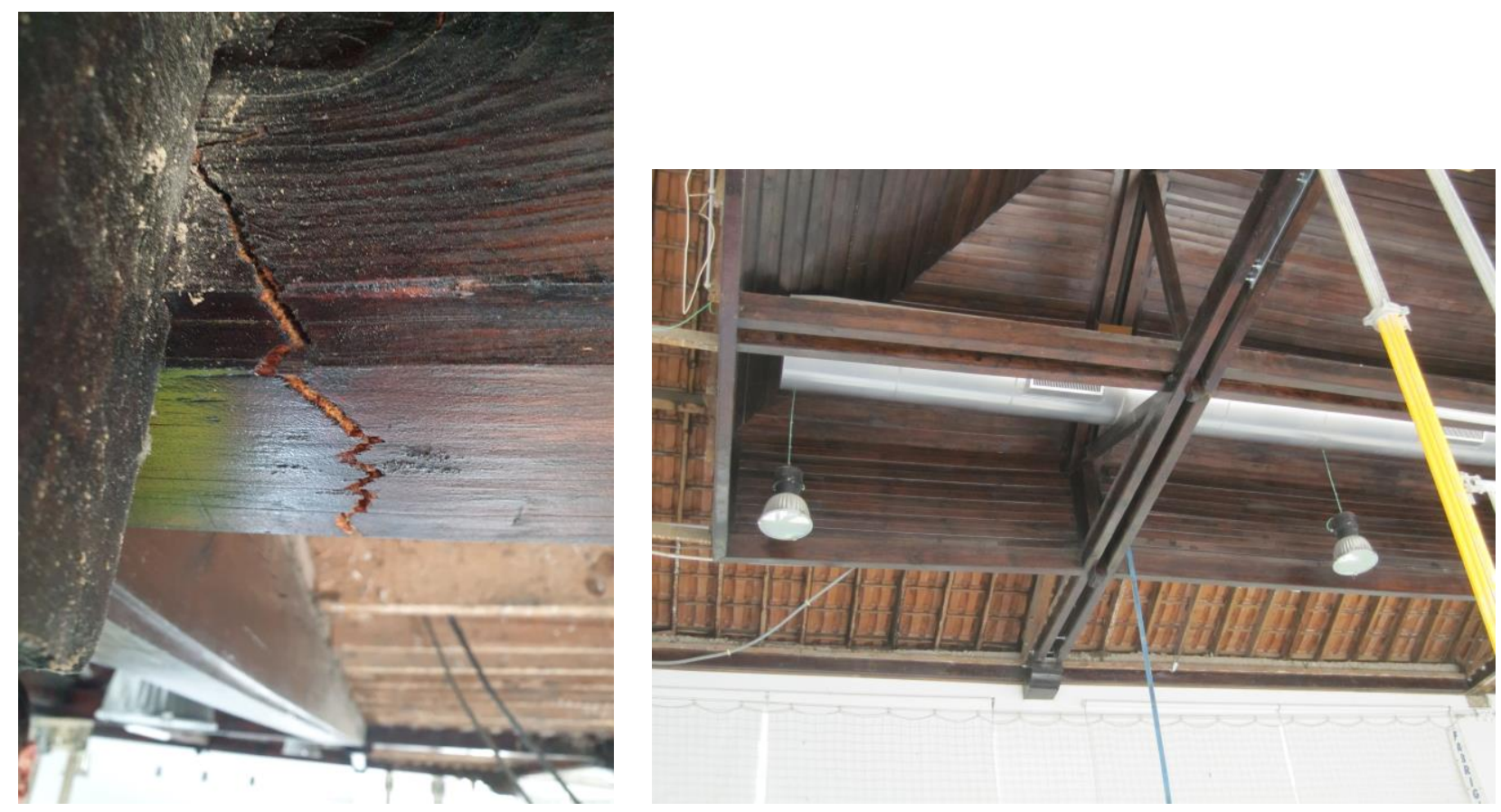

Figure 9. Broken tie-beam (left); Excessive ceiling slope (right) 


\section{Rehabilitation Project}

At a first stage, prior to the availability of the inspection and assessment report, the Parque Escolar E.P.E., owner of the building, considered the possibility of the roof demolition and its replacement by a steel structure. However, the recommendations of the report proposed the rehabilitation of the existing structure considering, namely:

- The generally good condition, requiring only the reinforcement of the trusses' supports;

- The reduced intrusiveness and cost of the repair;

- The architectural quality and patrimonial value of the existing structure.

These arguments prevailed and a decision was made in favour of the rehabilitation proposal.

\subsection{Strengthening and Rehabilitation of the Supports}

The structural analysis and the load evaluation and safety and stability assessment of the existing elements and connections was carried out first. The relevant provisions in EN 1991-1 (Eurocode 1- Actions in buildings) and EN 1995-1 (Eurocode 5-Timber structures) [15] were accounted for. As anticipated, from the awareness of the former practice in sizing and construction of timber structures, the cross-sections revealed comfortably fit to withstand the stresses produced by the standard load combinations. This expectation was not confirmed, however, for the failed connections, although they were strong enough to withstand the effects of the quasi-permanent load combination, as the in-service elapsed 70 years confirmed. Therefore, as the observed failure did not occur in the context of any abnormal and high-intensity load event, one assumes that the load-duration effect, possibly combined with a lower strength of those particular supports, either due to a lower timber grade or to local biologic attack, may have been the cause of the accident. In every case, it is symptomatic that the failure occurred in the central piece, in which the forces and stresses are double than those in the adjacent rafters or tie-beams connected by that element, as illustrated in Figure 5-a. Therefore, the key provision of the rehabilitation project consisted of the replacement of the central piece, in all the truss supports, by other with similar geometry but superior strength. Considering that two central pieces exist in each support, one joining the two rafters and the other the two tie-beams, and that they are connected according to the scheme in Figure 4-a, to allow for the equilibrium of horizontal forces, a V-shaped piece, made up with welded RHS, was designed as the replacement system. The width of the RHS is the same of that of the replaced timber pieces, as that dimension may not be change, so that the new element fits tightly between the double rafters/tie-beams. One branch of the "V" is connected to the double rafter and the other to the double tie-beam and the two branches are welded, ensuring the transmission of the horizontal forces. The system is as shown in Figure 10, where the steel element is represented on the left and the double timber elements, and its reinforcement, are represented on the right.

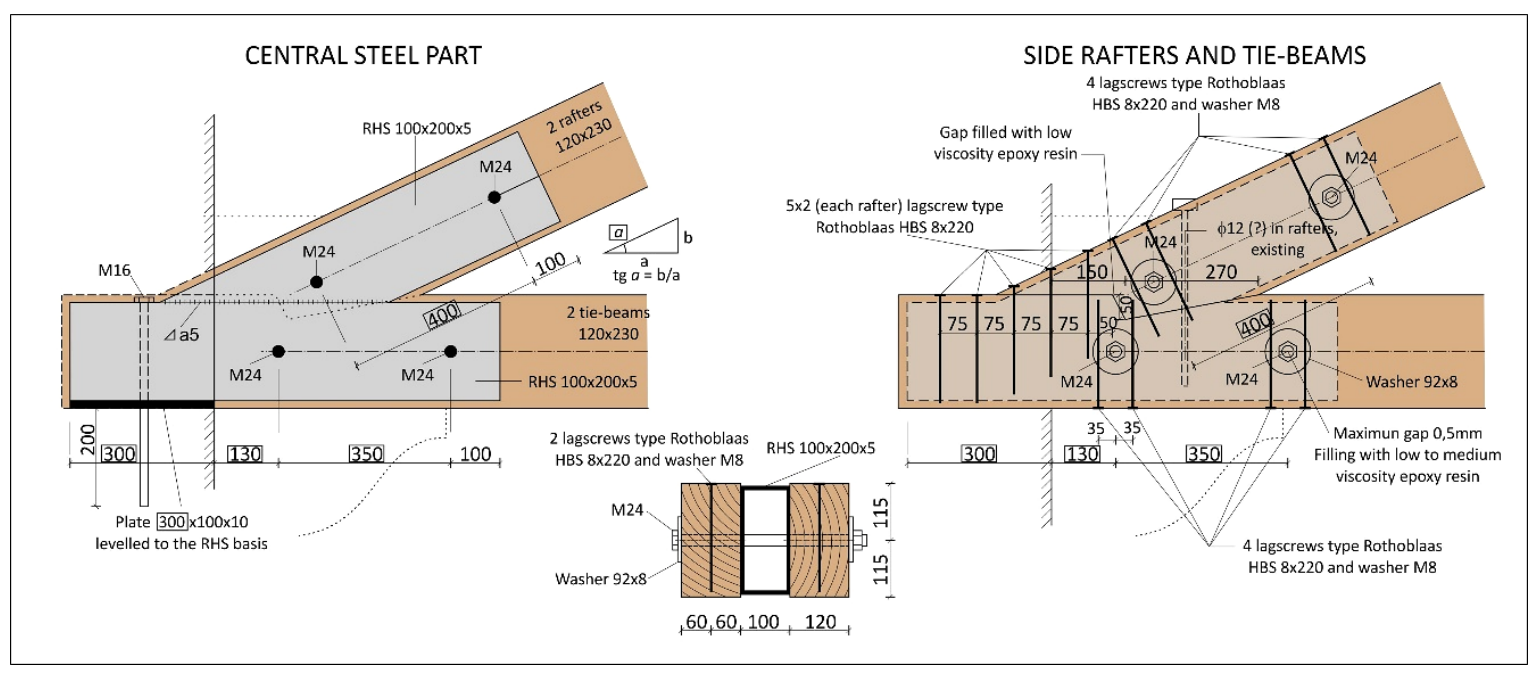

Figure 10. Strengthening/rehabilitation solution for the supports' connections

Given the uncertainty towards the condition of the shear toes of the tie-beam ends, which should be able to sustain the horizontal thrust from the rafters, the potential shear surface was strengthened with 5 pairs of lagscrews (tirefonds). One should emphasize, however, that the bolted connections between the timber elements and the central steel part were designed to withstand the whole axial load in the bars and, therefore, they are a redundant system of the rafter-tie beam carpentry joint, which is the traditional load transfer system.

In order to improve safety against perpendicular tension failure, 2 lagscrews were also driven in each side of the M24 bolted connections between the rafter/tie-beams and the steel central part. In the two collapsed supports, replacement of the broken rafters and tie-beams had to be done rather than just reinforcing the original elements. The joining of the old and new timber parts with reinforced epoxy-based prosthesis was first envisaged, but the lack of 
national companies certified to carry out that kind of intervention finally pushed the design to the conventional solution of external steel bolted plates (Figure 11). This solution was also used to repair the fracture shown in Figure 9-left.

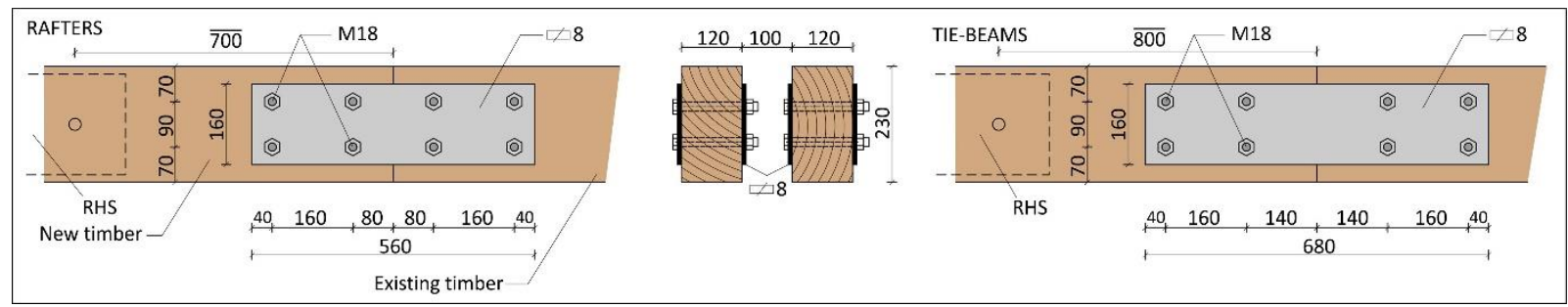

Figure 11. Connection between new and old rafter and tie-beam pieces

A similar solution to these was used to strengthen the "Jupiter-ray" connections, with the extra constraint that the holes were drilled beyond the outermost limit of the carpentry connection (Figure 12).

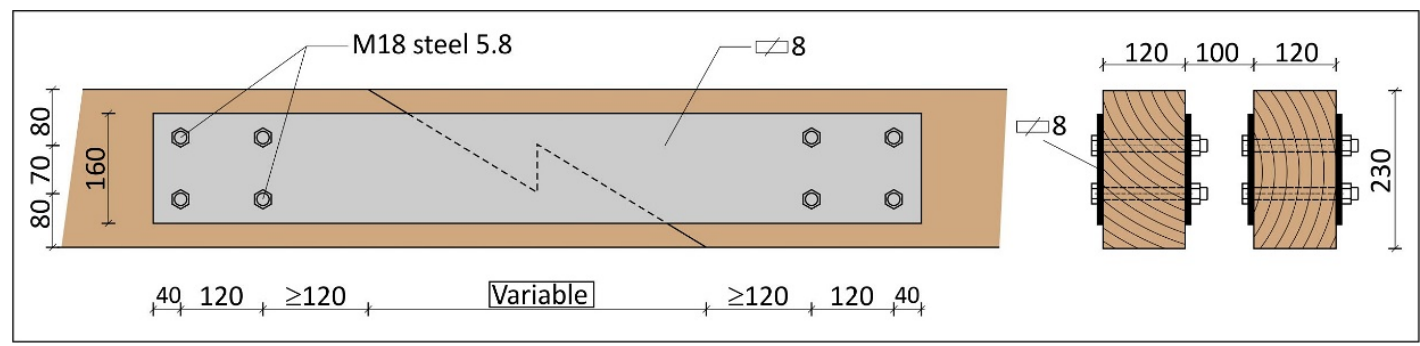

Figure 12. Strengthening of the 'Jupiter-ray' joints

\section{Execution Process}

\subsection{Propping of the Trusses}

The comparative advantage of the rehabilitation solution with respect to the replacement by a new steel structure essentially depended on the possibility of avoiding the dismantling of the timber trusses and, consequently, of the whole roof, carrying out only local interventions in those elements and zones to be repaired or strengthened. The replacement of the central timber pieces and/or of rafter/tie-beam segments prevented the normal structural behavior of the trusses. Therefore, in order to ensure its stability during the execution, those nodes close to the support being replaced/repaired had to be propped, to transmit the roof dead load directly to these temporary supports through the truss hangers. The truss half-span opposite to the support being repaired was not propped and kept working as a lattice structure, but with a reduced span and, consequently, different and much smaller stresses and deflections. The recovery of the original stress distribution required the unloading of the truss elements during the repairing works. To accomplish this, hydraulic jacks were used to uplift the tie-beam nodes to the design level. This provision should be combined with the removal of the roof tiles, to minimize the dead load during execution, but this procedure was skipped upon request of the contractor, given the considerable savings in execution time and costs and after confirming that this simplification led to a minor change on the temporary stress state of the propped truss.

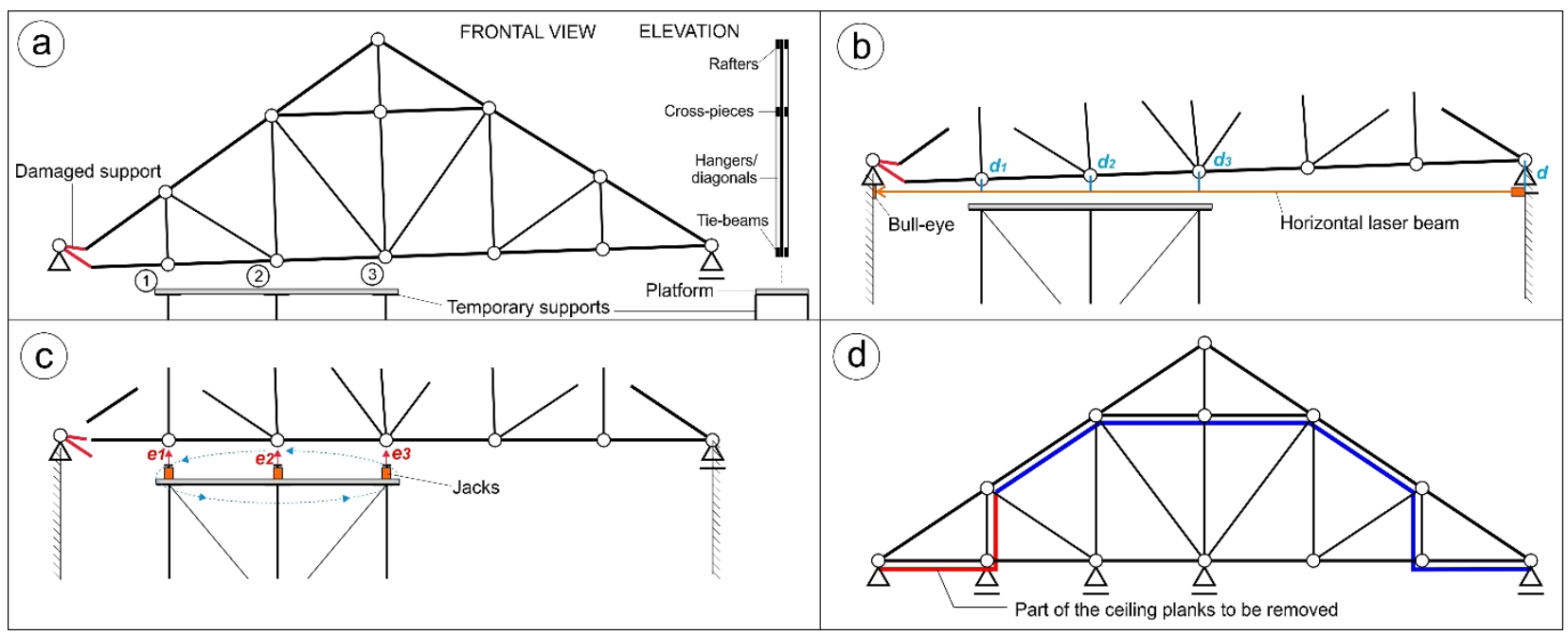

Figure 13. Execution process of the truss propping 
The erection procedure finally used, aimed at achieving the objective mentioned before, thus consisted of the following steps:

- Placement of propping supports under the nodes 1,2 and 3 (Figure 13-a) and in the middle plan of the truss, with a free gap of $0,30 \mathrm{~m}$ between the top of the props and the bottom of the nodes;

- Bracing of the props in both the truss in-plane and out-of-plane directions;

- Levelling of a laser beam and bull-eyes on the opposite supporting walls (Figure 13-b). With a ruler or a movable bull-eye, measure the distances $d_{l}, d_{2}$ and $d_{3}$ and, from these, the deflections $\left(e_{i}=d-d_{i}\right)$ of nodes 1,2 and 3 ;

- Use of hydraulic jacks placed on the top of the props to establish the horizontality of the tie-beam, iteratively and slowly increasing the force of the jacks under the nodes 1,2 and 3 , until uplifts of $-e_{i}(i=1,2,3)$ were measured (13-c);

- Removal of the ceiling planks between the broken support and the adjacent tie-beam node (Figure 13-d), in order to allow full access to the damaged elements;

- Start with the repair works described in Section 3.

\subsection{Repair-strengthening Works}

When the ceiling planks were removed and visual contact was established with the structural truss elements, the contractor expressed some doubts regarding the extent of biologic attack of some structural elements. To address this, a late visual inspection and a Resistograph (driller) campaign (Figure 14) were carried out, which confirmed the general good conservation condition of all the elements and, consequently, the execution could proceed as initially planned. The inspection program was as shown in Figure 15.

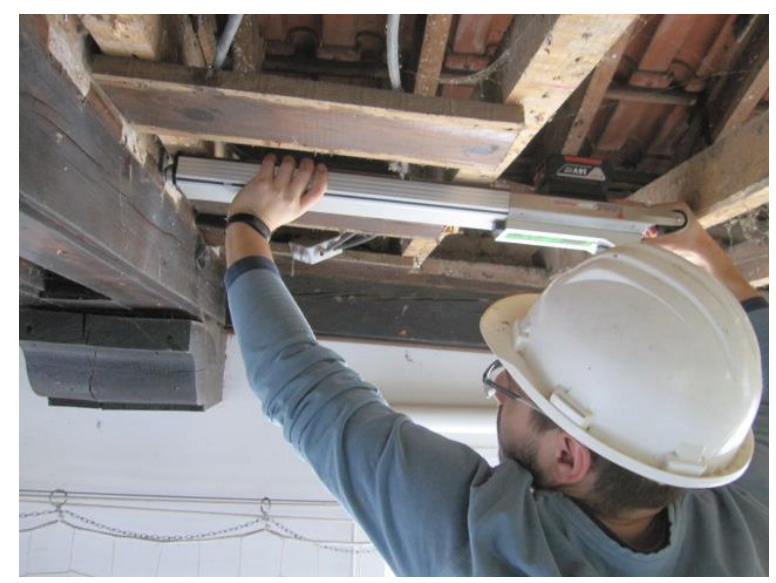

Figure 14. Assessment drillings

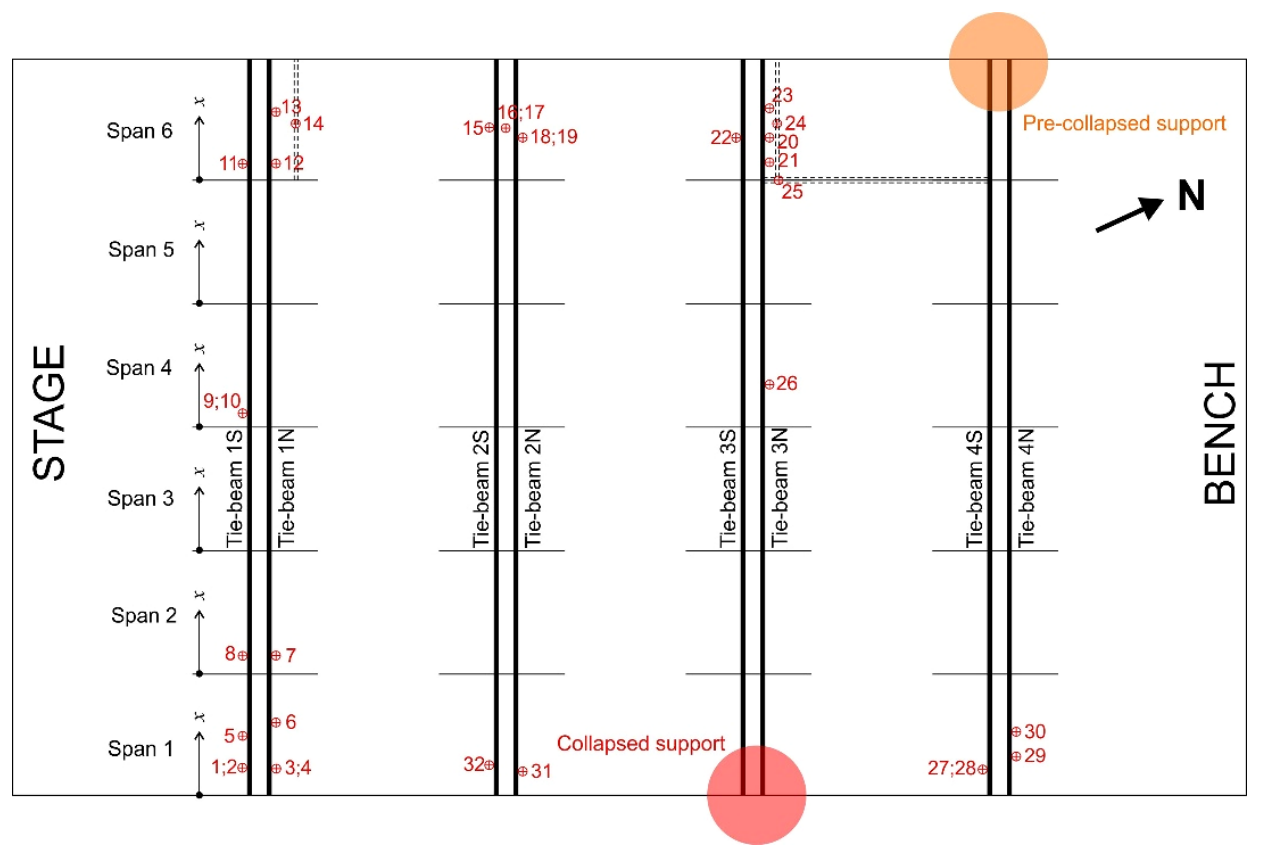

Figure 15. Resistograph drilling program 
Figure 16 shows some of the repair/strengthening elements, namely the steel V-shaped elements used to replace the central timber pieces at the supports, the repair prosthesis of the broken tie-beam shown in Figure 8-left and the steel plates used to reinforce all the Jupiter-ray splices.
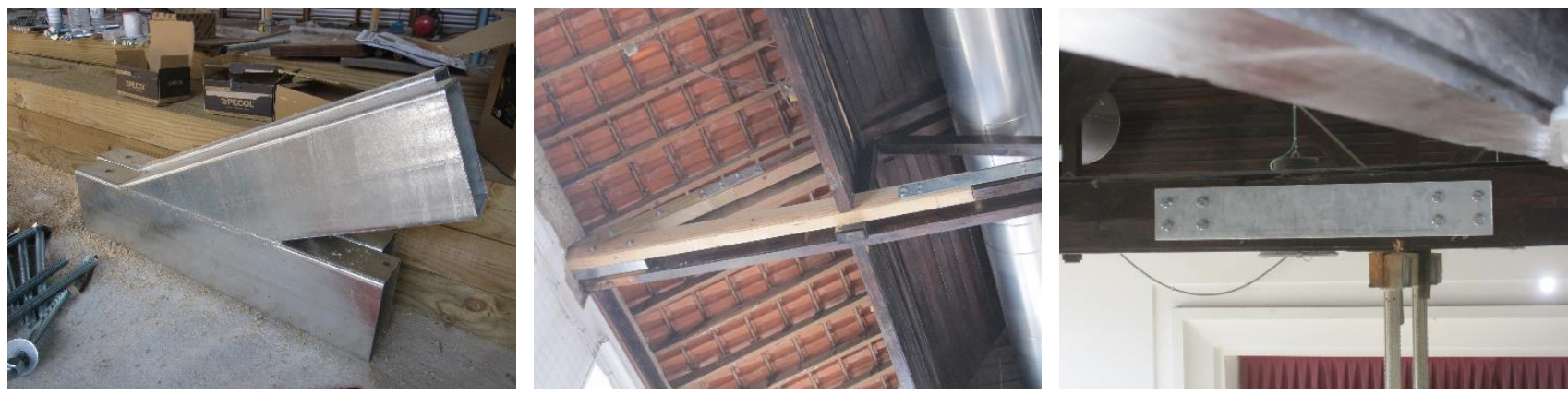

Figure 16. Execution: Steel central pieces (left); prosthesis at the broken tie-beam (centre); Jupiter rays' splices (right)

\section{Conclusion}

Following an atypical failure of timber roof trusses, caused by tension perpendicular to the grain and splitting of short wood bars joining twin rafters and twin tie-beams at the supports, a preliminary technical and economic assessment led to the decision of the rehabilitation of the existing trusses, rather than its replacement with a fully new steel structure. Although not conditioned by them from the beginning, the adopted solution exemplarily matches the ICOMOS recommendations and existing standards on rehabilitation of wood structures, while allowing to preserve the beautiful appearance of the 70-year old original trusses. The cost was about 2/3 of what was estimated for a steel solution, while the execution time was less than 2 months and carried out fully indoors, with no need of tiles and roof removal and minimum interference on the routines of the evolving areas. Although no theoretical innovation was involved and the rehabilitation project was based on current and established models and resources, it is believed that these advantages and also the discrete and original solution make this report worthy.

\section{Acknowledgement}

The author thanks Parque Escolar E.P.E., owner of the building, and ITECONS, the institute where the consultancy work was carried out, the permission for the publication of this work.

\section{Conflicts of Interest}

The authors declare no conflict of interest.

\section{References}

[1] Roca, Pere, Paulo B. Lourenço, and Angelo Gaetani. "Historic Construction and Conservation: Materials, Systems and Damage.” Routledge, Taylor and Francis, (2019).

[2] UNI (Ente Nazionale Italiano di Unificazione). UNI 11119 - Cultural heritage - Wooden artefacts - Load-bearing structures - On site inspections for the diagnosis of timber members, Milan, 2004 (in Italian).

[3] UNI (Ente Nazionale Italiano di Unificazione). UNI 11138 - Cultural heritage - Wooden artefacts - Building load bearing structures - Criteria for the preliminary evaluation, the design and the execution of works, Milan, 2004 (in Italian).

[4] AENOR (Asociación Española de Normalización y Certificación). UNE 41805-8-IN - Building diagnosis. Part 8: Pathological study of the structure of the building. Wooden structures. Madrid, 2009 (in Spanish).

[5] CEN (European Standardization Committee) - CEWN/TC250/SC5-N1217-Background Document on Carpentry connections, (2020).

[6] F. Arriaga, F. Peraza, M. Esteban, I. Bobadilla, F. García. "Intervención en Estructuras de Madera” (2002), AITIM, Madrid, Spain (in Spanish).

[7] Palma, Pedro, Helena Garcia, João Ferreira, João Appleton, and Helena Cruz. "Behaviour and Repair of Carpentry Connections - Rotational Behaviour of the Rafter and Tie Beam Connection in Timber Roof Structures.” Journal of Cultural Heritage 13, no. 3 (September 2012): S64-S73. doi:10.1016/j.culher.2012.03.002.

[8] Branco, Jorge Manuel, Maurizio Piazza, and Paulo J.S. Cruz. "Experimental Evaluation of Different Strengthening Techniques of Traditional Timber Connections." Engineering Structures 33, no. 8 (August 2011): 2259-2270. doi:10.1016/j.engstruct.2011.04.002. 
[9] Parisi, Maria A., and Maurizio Piazza. "Mechanics of Plain and Retrofitted Traditional Timber Connections." Journal of Structural Engineering 126, no. 12 (December 2000): 1395-1403. doi:10.1061/(asce)0733-9445(2000)126:12(1395).

[10] Villar, J.R., M. Guaita, P. Vidal, and F. Arriaga. "Analysis of the Stress State at the Cogging Joint in Timber Structures." Biosystems Engineering 96, no. 1 (January 2007): 79-90. doi:10.1016/j.biosystemseng.2006.09.009.

[11] Parisi, Maria Adelaide, and Cinzia Cordié. "Mechanical Behavior of Double-Step Timber Joints." Construction and Building Materials 24, no. 8 (August 2010): 1364-1371. doi:10.1016/j.conbuildmat.2010.01.001.

[12] Parisi, Maria A, and Maurizio Piazza. "Seismic Behavior and Retrofitting of Joints in Traditional Timber Roof Structures." Soil Dynamics and Earthquake Engineering 22, no. 9-12 (October 2002): 1183-1191. doi:10.1016/s0267-7261(02)00146-x.

[13] Parisi, Maria Adelaide, and Maurizio Piazza. "Seismic Strengthening and Seismic Improvement of Timber Structures." Construction and Building Materials 97 (October 2015): 55-66. doi:10.1016/j.conbuildmat.2015.05.093.

[14] ITeCons. Documento PJT.CNS014/18: Cobertura da sala polivalente da escola Secundária Alves Martins em Viseu - Projeto de recuperação estrutural (2018).

[15] EN, CEN. "1-1. Eurocode 5: Design of timber structures-Part 1-1: General-Common rules and rules for buildings." CEN, Brussels, Belgium (2004). 